\title{
Forecasting Shanghai containerized freight index by using time series models
}

\author{
Kaan Koyuncu' ${ }^{1}$ - Leyla Tavacioğlu ${ }^{2^{*}}$ iD \\ ${ }^{1}$ Muğla Sitkı Koçman University, Department of Transport Services, 48900 Muğla, Turkey \\ ${ }^{2}$ Istanbul Technical University, Maritime Faculty, Department of Basic Sciences, 34940 Istanbul, Turkey
}

\begin{tabular}{|c|c|}
\hline A R T & A B S T R A C T \\
\hline Article History: & Recently, the container shipping industry has become unpredictable due to volatility \\
\hline Received: 16.11 .2021 & and major events affecting the maritime sector. At the same time, approaches to estimating \\
\hline Received in revised form: 22.12 .2021 & container freight rates using econometric and time series modelling have become very \\
\hline Accepted: 23.12 .2021 & important. Therefore, in this paper, different time-series models have been explored that \\
\hline Available online: 29.12 .2021 & are related to the Shanghai Containerized Freight Index (SCFI). SMA, EWMA, and, SES, \\
\hline $\begin{array}{l}\text { Keywords: } \\
\text { Shanghai Containerized Freight Index } \\
\text { Volatility }\end{array}$ & $\begin{array}{l}\text { Holt Winter method are used to describe the data and model. Afterward, the Holt Winter } \\
\text { method and SARIMA was applied to model and predict the SCFI index. MAPE, RMSE, }\end{array}$ \\
\hline Freight rates & AIC, BIC are used to measure the performances of the models and predictions. We observe \\
\hline SARIMA & that the SARIMA model provides comparatively better results than the existing freight rate \\
\hline $\begin{array}{l}\text { Container } \\
\text { Holt Winter }\end{array}$ & $\begin{array}{l}\text { forecasting models while performing short-term forecasts on a monthly rate. Results } \\
\text { demonstrate that the increase will continue without losing momentum. }\end{array}$ \\
\hline
\end{tabular}

Please cite this paper as follows:

Koyuncu, K., \& Tavacioğlu, L. (2021). Forecasting Shanghai containerized freight index by using time series models. Marine Science and Technology Bulletin, 10(4), 426-434. https://doi.org/10.33714/masteb.1024663

\section{Introduction}

Nowadays, more and more companies are looking for driven decision-makers. Maritime industry intelligence and analytics departments and business managers have to regularly make forecasts of product sales, inventory, requirements, shipment rates, etc. Then, take strategic decisions based on these forecast values. For example, retail stores forecast sales.
They use data of the consumers' past purchases and try to forecast sales for the coming days. Similarly, energy companies forecast production demand of reserves, and price forecast of reserves are used to determine long-term investment plans whereas demand forecasts are used for short-term production planning and competitive pricing. Banks and lending institutions forecast new home purchases and venture capital firms forecast market potential to evaluate business plans. The

* Corresponding author

E-mail address: tavaciog@itu.edu.tr (L. Tavacioğlu) 
maritime industries operate in complex global markets and businesses are subject to external forces and constant environmental change. The ability to read, understand and respond effectively to the range of rapidly moving components that make up a market is essential to the modern company's survival. Forecasting is vital to increase profitability and save money in the maritime industry.

Freight prices are at their highest values in history. Container freight rates are breaking all-time records. World Container Index experienced a $480 \%$ increase by reaching $\$ 8,795.77$ for each $40 \mathrm{ft}$ container between January 2020 and August 2021 (Drewry, 2021). The reasons behind this increase can be listed as that the mobility which started with the pandemic period together with other factors such as maritime trade wars, previously established and strengthened joint service structures, alternative routes, empty container problems, oil price volatility, the ship that blocked the Suez Canal, the spread of vaccine and normalization, increasing demands, supply shortages, Christmas preparation in global trade, and expected rapid growth in world trade. This shows that a new era has begun in maritime trade in the light of recent developments.

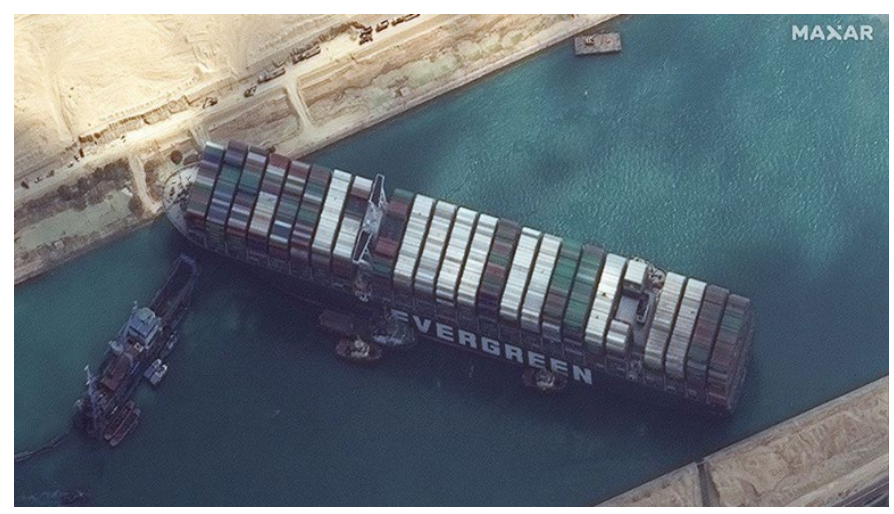

Figure 1. Ever Given: Ship that blocked Suez Canal (BBC, 2021)

A large container ship called Ever Given, owned by the Evergreen company, disturbed the sea traffic for 6 days in March 2021, when it went aground during its passage through the Suez Canal, which is the passage for $12 \%$ of world trade (Figure 1). This incident caused commercial delays and financial losses in supply chains around the world. It is estimated that there is a loss of an average of 50 billion dollars. Moreover, oil prices in international markets increased by $4 \%$ (BBC, 2021).

With such an extreme breaking point that is due to a ship blocked a canal for 6 days, the dimensions of the dangers facing the maritime industry can be seen quite clearly when compared to the global epidemic (pandemic) that lasted for months. Besides this, world trade is struggling with the empty container problem. Thus, many traders are facing challenges to deliver their export products to customers (Ship Technology, 2021).

Christmas preparations in global trade started early this year. Global buyers, who were unable to fill their shelves before Christmas due to the supply disruptions last year because of the pandemic, are in a rush to restock by moving their orders to an earlier time to avoid a similar situation. Experts warn about the acceleration of trade may cause a new crisis in the container market, and besides the equipment shortage, freight prices, which have increased by $300 \%$ in the last year and a half, may have an increasing trend (Dunya, 2021).

Forecasting is an important tool for maintaining the competitiveness of container lines and ports, formulating appropriate short-medium term strategies, and planning. In times of crisis or when all circumstances are normal, the importance of forecasting can be clearly noticed. Major fluctuations during the pandemic period affect index rates. Shanghai Containerized Freight Index (SCFI), one of the most important indices, is regarded as an important evaluation factor for container shipping in the maritime industry. SCFI is also a solid indicator in terms of supply and demand balance, container shipping, world trade movement, and the shipping industry.

SCFI focuses on Shanghai export container transport market spot rates, which are generally considered to be periodical and more sensitive. Shanghai export container transport market spot rates include a composite index, 15 shipping routes, and freight rates. The freight indices reflect the ocean freight and the associated seaborne surcharges of individual shipping routes on the spot market, where: Shipping routes: major container trade routes export from Shanghai to the following regions: Europe, Mediterranean Sea, US west coast, US east coast, Persian Gulf, Australia/New Zealand, West Africa, South Africa, South America, West Japan, East Japan, Southeast Asia, Korea. SCFI refers to volume weighted average prices of space book on spot market by common shippers, which are not influenced by peculiarity of shippers' enterprises or container volume. (Shanghai Shipping Exchange, 2020).

The composite index is the weighted average of all routes: the average spot freight rate of the specific route is divided by average price of its base period. The result multiplies its weighting and its base period index to obtain a value of each route. All the route values shall then add up to obtain the total value (Shanghai Shipping Exchange, 2020).

Forecasting is one of the most significant elements for all types of industries and the maritime industry is not an exception. Since it is impossible to predict the events that affect 
the shipping market and they happen suddenly, the changes in the market are also fluctuating and stochastic (Goulielmos et al., 2009).

However, such cycles and tendencies are not a new concept in the shipping industry. In fact, these are the integrated part of the industry for centuries (Stopford, 2009). Therewithal, being able to predict some of these swings can easily help carriers and shippers to capitalize on the fluctuations by allowing them to make the right decisions at the right times (Dixon, 2010).

In literature, several forecasting studies use maritime trade indices and volumes. The first study on time series is conducted by Klein \& Verbeke (1987) and is the study carried out for the Antwerp port by using univariate time series with monthly data in Antwerp port. A multivariate time series model was used in another study for steel traffic flow in the Antwerp port (Klein \& Verbeke, 1987). A long-term predictive value interval model was developed for forecasting the SCFI by fuzzy time series (Chou, 2017). Munim \& Schramm (2017) proposed a state-ofthe-art volatility forecasting method for container shipping freight rates. Another article on forecasting explored the use of SARIMA models in forecasting containers throughout several major international container ports while taking into consideration seasonal variations (Farhan \& Ong, 2018). Shu et al. (2014) forecasted both freight and container outputs for Hong Kong and Kaoshsiung ports with ARIMA and Grey Model and modified with Fourier to increase the accuracy of these two models. Pang \& Gebka (2017) used SARIMA, Additive Seasonal Holt-Winters (ASHW), Multiplicative Seasonal Holt-Winters (MSHW), and Vector Error Correction Models (VECM) to forecast the container output of Tanjunk Priok port, which is Indonesia's largest port.

In this paper, different time-series models have been explored that are related to the SCFI index. Different models and approaches such as SMA, EWMA, and, SES, Holt Winter method are used to describe the data and model. the Augmented Dickey-Fuller (ADF) was applied test on the trends and seasonality (time-invariant), which have been adjusted from the series so that the time series model can be applied. Later on, ACF and PACF have been calculated so that the time series can be determined for the model. For the model and forecasting of the SCFI index, the SARIMA and Holt Winter methods have been utilized. Moreover, in the evaluation of the models' and predictions' performances, the MAPE, RMSE, AIC, and BIC have been used.

\section{Materials and Methods}

In the study, Shanghai Containerized Freight Index data from February 2016 to July 2021 was used. These data are modeled with the Python programming language. The proposed SCFI index forecasting methodology includes the following stages: describing the data and model, model identification and estimation, evaluation and forecasting, results.

\section{Data and Model Description}

Time series are well-defined data sets collected at variable time intervals and at equal time intervals. Analysis of time series includes some stages. Firstly, the data to be modeled should have a normal distribution. If the data is not normally distributed, the data will need to be converted to ensure the normal distribution of data. The conversion of data (such as square root or logarithms) ensures the fixation of the variance in a series with varying variation (Dasyam et al., 2015).

Later on, whether the series is stationary or not. Box-Jenkins model assumes that the time series is stationary. A stationary time series has a stationary mean, stationary variance, and stationary autocorrelation. These values are determined by using autocorrelation (ACF) and partial autocorrelation functions (PACF) and Dickey-Fuller (ADF) test (Awal \& Siddique, 2011). Correlograms (ACF and PACF graphs) can show a stationarity pattern or a unit root with significant lags. A more subjective way to evaluate is using (augmented) DickeyFuller (ADF) test statistics (Dickey \& Fuller, 1979). The null hypothesis is that the series has a unit root. The alternative hypothesis is that the time series is stationary (or trendstationary).

\section{Model Identification and Estimation}

In the study, smoothing methods and the Box-Jenkins method were used in time series analysis.

A simple moving average (SMA) is an arithmetic moving average calculated by adding recent prices and then dividing that figure by the number of time periods in the calculation average. SMA is given as follows:

$S M A_{t+s}=\sum_{s=-h}^{h}(2 h+1)^{-1} y_{t+s}, \quad t=h+1, h+2, \ldots, n-h$

With $(t+s)$ observations of $y_{t+s}, h$ denotes a positive integer, $s$ is the seasonal indices, $t$ is the time period (Khogali et al., 2002). 
Exponentially Weighted Moving Average (EWMA) will allow us to reduce the lag effect from SMA and EWMA will put more weight on values that occurred more recently. EWMA formula is as follows:

$E W M A_{t}=\alpha y_{t}+(1-\alpha) E W M A_{t-1}, \quad t=h+1, h+2, \ldots, n-h$

where $\alpha$ is the weight and $t$ is the time period of the series. EWMA is a recursive process that continues until reaches the $E W M A_{0}$ (Lucas \& Saccucci, 1990).

The Holt-Winters method is a very common time series forecasting procedure capable of including both trend and seasonality. The method is also called "double exponential smoothing". Holt-Winter is used for exponential smoothing to make short-term forecasts by using "additive" or "multiplicative" models with increasing or decreasing trends and seasonality. Smoothing is measured by beta and gamma parameters in Holt's model. The Holt-Winters seasonal method consists of the forecast equation and three smoothing equations which are one for the level $l_{t}$, one for the trend $b_{t}$, and one for the seasonal component $s_{t}$, with smoothing parameters $\alpha, \beta, \gamma, m$ is used to define the seasonality of frequency. The component form for the additive model is as follows:

$y_{t+h \mid t}=l_{t}+h b_{t}+s_{t+h-m(k+1)}$,

$l_{t}=\alpha\left(y_{t}-s_{t-m}\right)+(1-\alpha)\left(l_{t-1}+b_{t-1}\right)$,

$b_{t}=\beta^{*}\left(l_{t}-l_{t-1}\right)+\left(1-\beta^{*}\right) b_{t-1}$,

$s_{t}=\gamma\left(y_{t}-l_{t-1}-b_{t-1}\right)+(1-\gamma) s_{t-m}$,

The component form for the multiplicative model is as follows:

$$
\begin{aligned}
& y_{t+h \mid t}=\left(l_{t}+h b_{t}\right) s_{t+h-m(k+1)}, \\
& l_{t}=\alpha\left(y_{t} / s_{t-m}\right)+(1-\alpha)\left(l_{t-1}+b_{t-1}\right), \\
& b_{t}=\beta^{*}\left(l_{t}-l_{t-1}\right)+\left(1-\beta^{*}\right) b_{t-1}, \\
& s_{t}=\gamma\left(y_{t} / l_{t-1}-b_{t-1}\right)+(1-\gamma) s_{t-m},
\end{aligned}
$$

where $k$ is the integer part of $(h-1) / m$, which ensures that the estimates of the seasonal indices used for forecasting come from the final year of the sample. The level of the equation shows a weighted average between the seasonally adjusted observation $\left(y_{t}-s_{t-m}\right)$ and the non-seasonal forecast $\left(l_{t-1}+\right.$ $\left.b_{t-1}\right)$ for time $t$. The trend equation is identical to Holt's linear method. The seasonal equation shows a weighted average between the current seasonal index, $\left(y_{t}-l_{t-1}-b_{t-1}\right)$, and the seasonal index of the same season last year. Triple exponential smoothing applies exponential smoothing three times, which combines double exponential smoothing (Holt's method) and simple exponential smoothing. Thus, the method is useful for determining the level, trend and seasonality, and rapidly makes us of them in a forecast.

Box-Jenkins method is based on discrete and linear stochastic processes. Major Box-Jenkins forecasting models are autoregressive (AR) integrated (I) moving average (MA) and seasonal (S) autoregressive integrated moving average. The general structure of this model is represented as ARIMA ( $p, d$, q) $\times(\mathrm{P}, \mathrm{D}, \mathrm{Q})$. The main approach in the Box-Jenkins model is based on the combination of the value of the currently studied variable and the random shocks with the weighted sum of the previous values. Whether the series is stationary or not and it has a seasonal effect is decisive in model selection. Therefore, firstly, the properties of the time series are revealed, and a suitable model will be tried to be find.

Time series usually consists of cyclical properties that seasonal variation is used to eliminate the effects of seasonality. These models are named as SARIMA models. SARIMA models are often described as $\operatorname{SARIMA}(p, d, q) \times(P, D, Q) \_S$ where $P$ is the order of the seasonal autoregressive (SAR) part. $D$ is the order of the seasonal differencing. $Q$ is the order of the seasonal moving-average (SMA) process. $S$ is the length of the seasonal cycle. SARIMA model's formula is as follows:

$\varphi(B) \emptyset\left(B^{S}\right) \nabla^{d} \nabla_{S}^{D} y(t)=\theta(B) \vartheta\left(B^{S}\right) \varepsilon(t)$

with

$$
\begin{gathered}
\emptyset\left(B^{S}\right)=1-\emptyset_{1} B^{S}-\cdots-\emptyset_{P} B^{P S} \\
\vartheta\left(B^{S}\right)=1+\vartheta_{1} B^{S}+\cdots+\vartheta_{Q} B^{Q S} \\
\nabla_{S}^{D} y(t)=\left(1-B^{S}\right)^{D} x(t)
\end{gathered}
$$

In the formula, $\nabla$ is the difference operator; $\varphi(B)$ is the autoregressive polynomial of $p$ with autoregressive parameter of $\varphi_{1}, \varphi_{2}, \ldots, \varphi_{p} ; \theta(B)$ denoted moving average polynomial of $q$, as the moving average parameter described as $\theta_{1}, \theta_{2}, \ldots, \theta_{q}$; stationary time series reflects as $\nabla^{d} x(t) ; \varepsilon(t)$ is independent white noise and suits the Gaussian distribution.

$\varnothing\left(B^{S}\right)$ indicates seasonal autoregressive polynomial as $\emptyset_{1}, \emptyset, \ldots, \emptyset_{P}$ acts as the seasonal autoregressive parameter. 
$\vartheta\left(B^{S}\right)$ stands for seasonal moving average polynomial as $\vartheta_{1}, \vartheta, \ldots, \vartheta_{Q}$ acts as seasonal mobbing average parameter; $\nabla_{S}^{D}$ signifies the seasonal difference which goes through the $D$ order (Yang et al., 2017).

\section{Evaluation and Forecasting}

In order to evaluate the forecasting model, the following evaluation criteria are introduced; where $y(t)$ is the actual value of a point for the given time period $t, n$ is the total number of fitted points, and where $y(t)$ is the actual value of a point for given time period $t, n$ is the total number of fitted points, and $y \widehat{(t)}$ is the fitted forecast value for the time period $t$ (Agrawal et al., 2018).

RMSE (Root mean square error):

$R M S E=\sqrt{\frac{\sum_{t=1}^{n}(y(t)-y(\widehat{t}))^{2}}{n}}$

MAPE (Mean absolute percentage error):

$M A P E=\frac{100}{n} \sum_{t=1}^{n}\left|\frac{y(t)-y \widehat{(t)}}{y(t)}\right|$

Root mean square error is an absolute measure of error that squares deviations to prevent positive and negative deviations from canceling each other.

Mean absolute percent error is a relative measure of error that uses absolute values to prevent positive and negative errors from canceling each other and uses relative errors to enable you to compare the predictive accuracy between time series models.

AIC and BIC measure the model's prediction error and are used for model selection. Given a set of constructed models for the series, the model with the minimum AIC, BIC values is preferred.

Akaike information criterion (AIC):

$A I C=2 k-2 \ln (L)$

Bayesian information criterion (BIC):

$B I C=k \ln n-2 \ln L$

where $k$ is the number of estimated parameters, $n$ is the time period of the series, and $L$ is the maximum value of likelihood functions (Burnham \& Anderson, 2004).

\section{Results and Discussion}

In the period from February 2016 to August 2021, SCFI is shown in Figure 2.

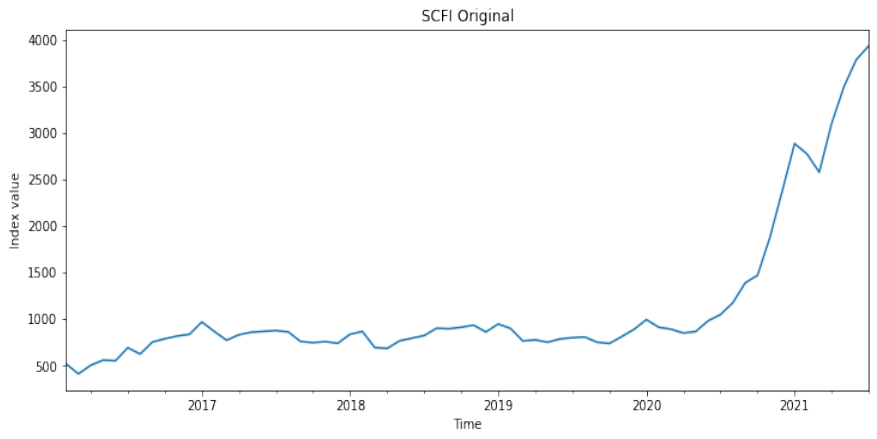

Figure 2. Time series plots of original SCFI

First, we focused on the comparison of Exponentially Weighted Moving Averages and Simple Moving Averages to determine the performance and complexity. The results are shown in Figure 3. The comparison includes the data between February 2016 and August 2021.

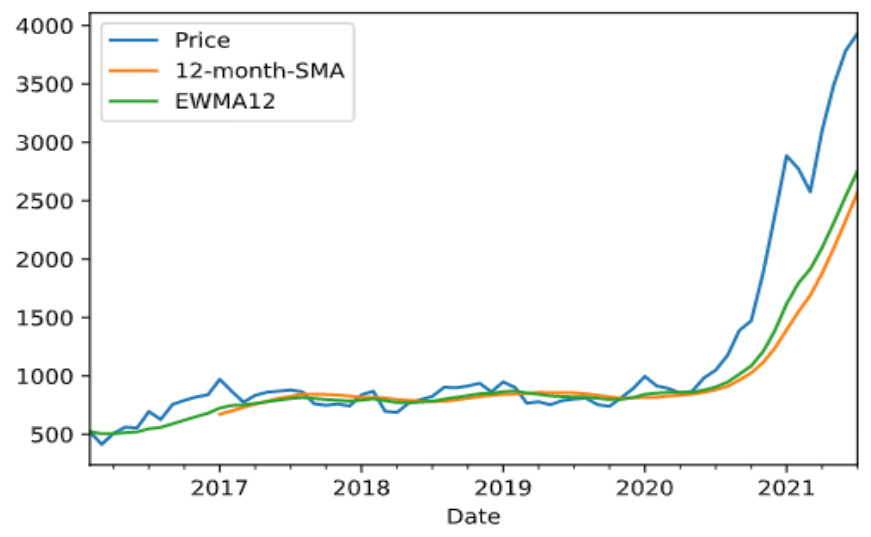

Figure 3. Simple moving averages to exponentially weighted moving averages

It is shown that this technique does a poor job of forecasting when there is a trend in the data as seen in Figure 3. As shown in the Figure 3, traders with a short-term perspective may not care about which average is used, since the difference between the two averages is usually a matter of mere cents. In the next section, we'll look at Simple Exponential Smoothing, Double and Triple Exponential Smoothing with the Holt-Winters Methods.

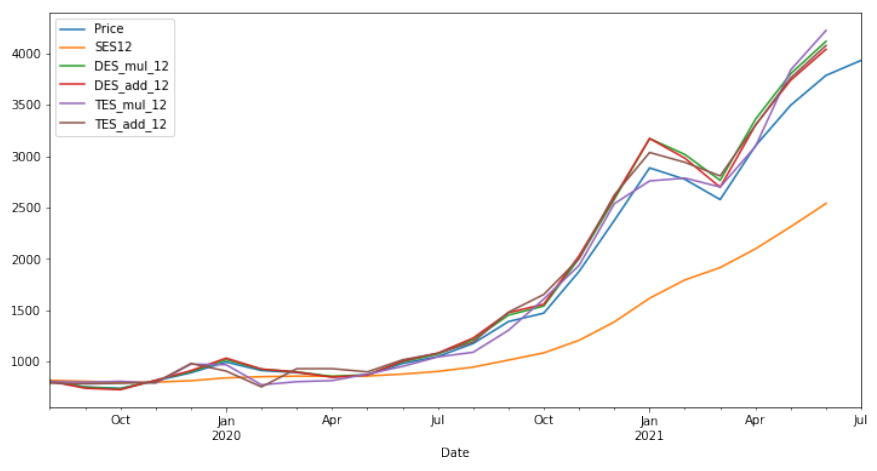

Figure 4. Comparison of model performances 
In this section, we are going to focus on extending our models for future forecasts. To do this, we are going to divide our current data into testing and training sets and then work on the trained model to evaluate its performance. Because of the importance of forecast accuracy, a test should be performed to verify forecast accuracy by comparing forecast values with observational values. (Chen et al., 2018). According to Farhan \& Ong (2018), while measuring forecast accuracy, it is better to use the combination of different measures to evaluate the forecast accuracy. MAPE and MAE are two of these combinations.

We can also address different types of change (growth/decay) in the trend. Our time series displays an exponential (curved) trend. We use a multiplicative adjustment. In Figure 4, we can see that Trible Exponential Smoothing is a much better representation of the time-series data. Although minor, it does appear that a multiplicative adjustment gives better results. Note that the green line almost completely overlaps the original data. RMSE and MAPE values were given in Table 1 . In finding the performances of the resulting models, performance evaluation formulas provided in equations (1) and (2) were used. Also, forecast values for the August 2021- March 2022 periods are provided in Table 2.

Table 1. The Holt-Winters Methods prediction outcome and performance evaluation

\begin{tabular}{lll}
\hline SCFI & RMSE & MAPE \\
\hline The Holt-Winters Methods & 743.61 & 649.30 \\
\hline
\end{tabular}

Table 2. The forecast values of SCFI by Using Holt-Winters Methods

\begin{tabular}{lc}
\hline Month & Forecast Values \\
\hline $2021-08-01$ & 4673.516318 \\
$2021-09-01$ & 5308.626677 \\
$2021-10-01$ & 5517.084727 \\
$2021-11-01$ & 6834.825919 \\
$2021-12-01$ & 8140.522746 \\
$2022-01-01$ & 9427.757152 \\
$2022-02-01$ & 9072.097432 \\
\hline
\end{tabular}

For time series modeling, time series data is said to be stationary if it does no exhibit trends or seasonality. That is, the mean, variance and covariance should be the same for any segment of the series and are not functions of time. There is a statistical hypothesis under this test.
$H_{0}$ : Data has unit root and is non-stationary;

$H_{1}$ : Data has no unit root and is stationary

The Augmented Dickey-Fuller (ADF) test is applied for testing the stationarity for the data series presented in Table 3.

Table 3. ADF test results for evaluating stationarity

\begin{tabular}{lccc}
\hline SCFI & Original & $\begin{array}{c}\text { 1st order } \\
\text { difference }\end{array}$ & 2nd order difference \\
\hline $\begin{array}{l}\text { ADF } \\
\text { (p-value) }\end{array}$ & 1.000 & 0.161 & $<0.000188$ \\
\hline
\end{tabular}

From the Table 3, after second order difference, the $p$ value is very less than the significance level of $5 \%$ and hence one cannot accept the null hypothesis $\mathrm{H}_{0}$ and make a decision that data series are stationary.

Decomposition of time series is applied to describe the trend and seasonal factors in a time series observation. When we decompose a time series into components, we usually combine the trend and cycle into a single trend-cycle component. Thus, we think of a time series as comprising three components: a trend-cycle a seasonal, and a remainder component. In Figure 5, although small in scale compared to the overall values, there is a definite annual seasonality. The plot shows the decomposition of our time series data in its seasonal component, its trend component, and the remainder (Figure 5).

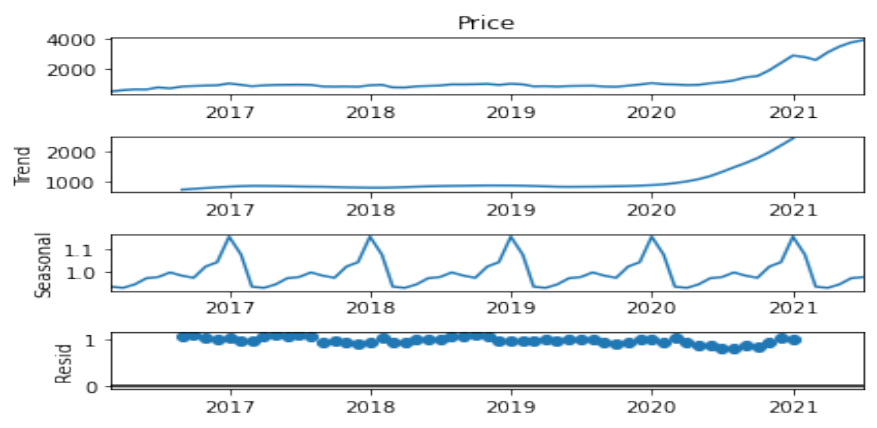

Figure 5. Decomposition of time series

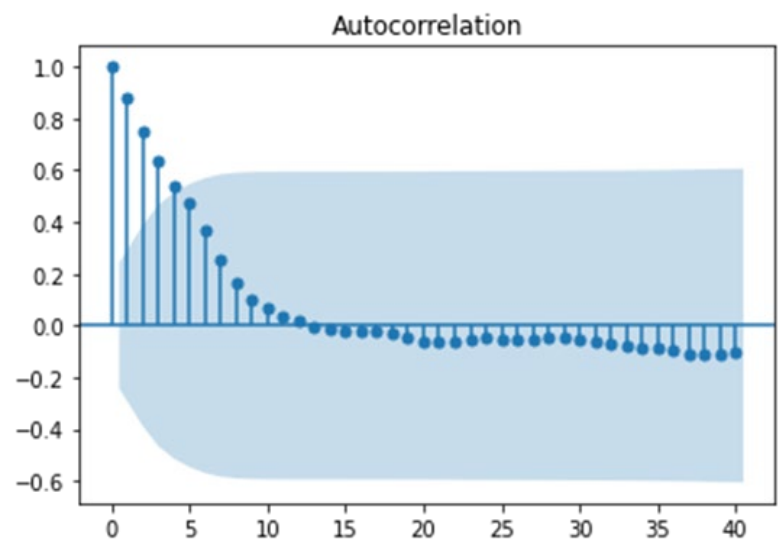

Figure 6. ACF plot of SCFI 


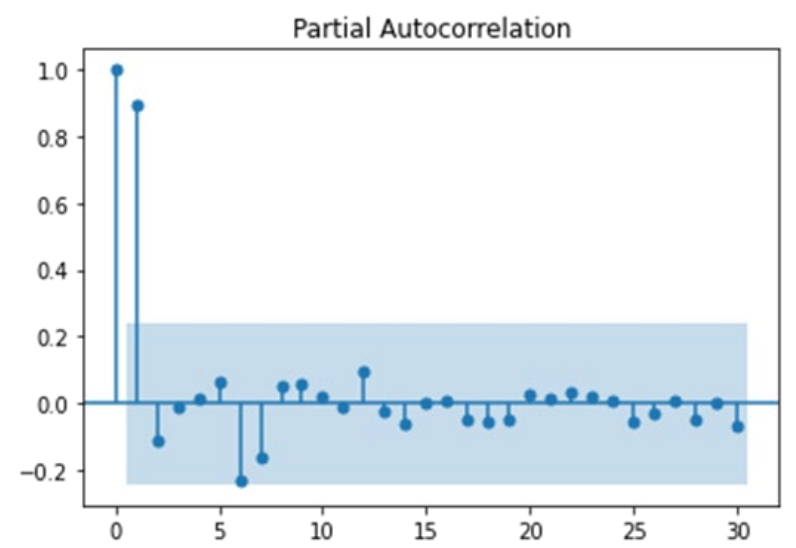

Figure 7. PACF plot of SCFI

The ACF and PACF plots helps us to confirm stationarity. The data are clearly non-stationary, with some seasonality, so we will first take a seasonal difference. The seasonally differenced data are shown in Table 3. The ACF and PACF plots of SCFI are examined and the degrees of seasonal and nonseasonal autoregression (AR) and moving average (MA) processes are determined. The linear decline of ACF is slow and that there is a significant meaningful block in PACF for SCFI. (Figure 6 and Figure 7).

Following is the sample PACF for this series. The first 2 lag value is statistically significant, whereas partial autocorrelations for all other lags are not statistically significant. According to the plot of the residuals in Figure 5. Residuals are normally distributed and follows a linear trend. Overall, the model shows good forecasting accuracy and used to predict future values. The model's forecast accuracies were calculated and compared by RMSE and MAPE. The RMSE and MAPE in SARIMA are also relatively low. The selected model shows good forecasting accuracy of the testing set. Considering that the second difference in the series is also stationary, the SARIMA $(0,2,3)$ $(1,0,0)_{12}$ model is chosen as the appropriate model. The selected model is verified to be appropriate using the stepwise model selection method.

The comparison of the Holt-Winters methods and SARIMA with model prediction outcome and performance evaluation is shown in Table 4. SARIMA marginally performed with a tightly lower errors when compared to the Holt-Winters. The SARIMA models, where error values are lower, are found more suitable models for forecasting SCFI. According to the results in Table 5 , SARIMA $(0,2,3)(1,0,0)_{12}$ is the found the most suitable model for forecasting SCFI.

Since model performance and diagnostics are controlled, the forecasting results can be examined 6-month forecasting is utilized with the SARIMA models. The forecasted values are also shown in Table 6.
Table 4. SARIMA and the Holt-Winters Methods prediction outcome and performance evaluation

\begin{tabular}{lcc}
\hline SCFI & RMSE & MAPE \\
\hline SARIMA $(0,2,3)(1,0,0)_{12}$ & 338.60 & 318.23 \\
Holt-Winters Methods & 561.14 & 519.867 \\
(Double Exponential Smoothing) & & \\
$\begin{array}{l}\text { Holt-Winters Methods } \\
\text { (Triple Exponential Smoothing) }\end{array}$ & 3727.24 & 3037.74 \\
\hline
\end{tabular}

Table 5. SARIMA models prediction outcome and performance evaluation (AIC and BIC)

\begin{tabular}{lll}
\hline SCFI & AIC & BIC \\
\hline SARIMA $(0,2,0)(1,0,1)_{12}$ & 819.35 & 830.22 \\
SARIMA $(1,2,0)(1,0,0)_{12}$ & 815.93 & 827.07 \\
SARIMA $(0,2,1)(0,0,1)_{12}$ & 799.52 & 812.17 \\
SARIMA $(0,2,1)(1,0,1)_{12}$ & 798.17 & 810.19 \\
SARIMA $(1,2,1)(1,0,0)_{12}$ & 798.06 & 810.17 \\
SARIMA $(0,2,3)(1,0,1)_{12}$ & 794.02 & 805.12 \\
SARIMA $(0,2,2)(0,0,2))_{12}$ & 798.20 & 810.21 \\
SARIMA $(0,2,3)(0,0,0)_{12}$ & 793.87 & 804.59 \\
\hline
\end{tabular}

When the forecasting results are shown with graphs, SCFI forecasting results are showed that the increase will continue (Figure 8).

Table 6. The forecast values of SCFI by Using SARIMA

\begin{tabular}{lc}
\hline Month & Forecast Values \\
\hline $2021-08-01$ & 4186.648130 \\
$2021-09-01$ & 4555.021128 \\
$2021-10-01$ & 4821.787789 \\
$2021-11-01$ & 5228.400601 \\
$2021-12-01$ & 5674.845754 \\
$2022-01-01$ & 6127.352350 \\
$2022-02-01$ & 6310.557688 \\
\hline
\end{tabular}

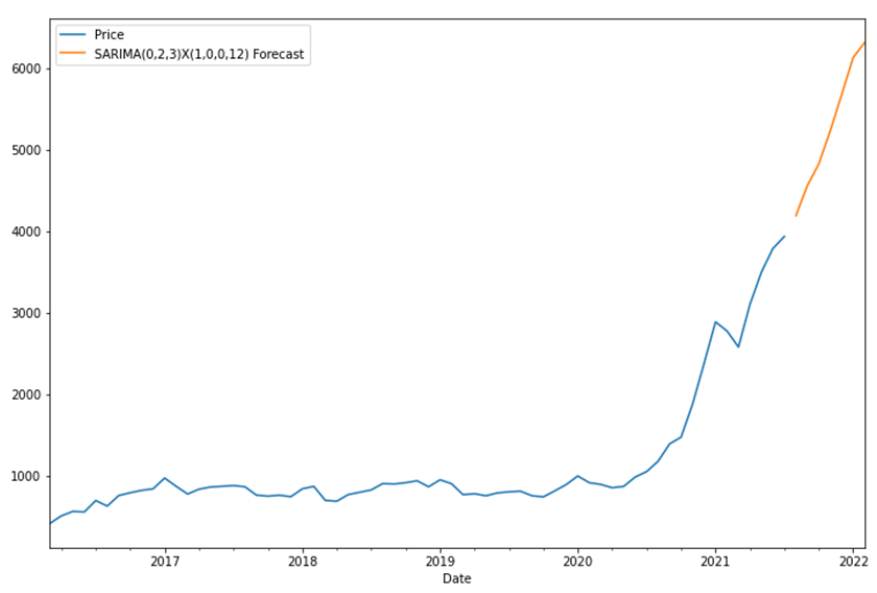

Figure 8. Forecasting of SCFI 


\section{Conclusion}

In this study, we have tried to contribute to the improvement of the forecast accuracy of SCFI by using two different time series modelling approaches and appropriate criteria to provide the assumptions of the approaches. For this purpose, SCFI data was examined by Holt-Winters and SARIMA methods. The study results demonstrate SARIMA model seems to be more precise and accurate model. SARIMA model has the minimum MAPE and RMSE values when compared with Holt-Winters. As a result of time series analysis, the chosen SARIMA model can be used to predict future values because the forecasting accuracy is acceptable. It was found that the most suitable model is SARIMA $(0,2,3)(1,0,0)_{12}$. In line with the determined SARIMA model, forecast values for the period August 2021-February 2022 have been calculated. According to the results of the analysis, it is predicted that the increase will continue without losing momentum. Since the beginning of 2021, container shipping spot freight rates have continued to rise due to the major imbalance between demand and effective maritime container transport capacity. The Shanghai Containerized Freight Index (SCFI) rose above 4,000 points for the first time in history. This increase can be associated with goods that are unable to be transported due to pandemic (lockdown), the intensive transportation of the goods that are kept in stock, and the increasing demands before Christmas, blocking off the Suez Channel by Evergreen, which happened suddenly during the transportation process that started after the pandemic, short-term breaks in world supply chains, empty container problem due to above-mentioned facts and the pandemic, and rises in inflation in the world. As a result of these developments, it is seen that the limited ship capacity leads to an increase in the freights in this current situation where transportation costs are increasing. Shipping market analysts can benefit from the performance of the proposed satisfactory forecasting models and integrate them into their administrative toolkits.

\section{Acknowledgements}

This study was produced from the doctoral dissertation of the first author.

\section{Compliance With Ethical Standards}

\section{Authors' Contributions}

KK: Validation, Investigation, Data curation, Writingoriginal draft, Methodology, Visualization.
LT: Conceptualization, Writing- review \& editing, Supervision.

\section{Conflict of Interest}

The authors declare that they have no known competing financial interests or personal relationships that could have appeared to influence the work reported in this paper.

\section{Ethical Approval}

For this type of study, formal consent is not required.

\section{References}

Agrawal, R. K., Muchahary, F., \& Tripathi, M. M. (2018). Long term load forecasting with hourly predictions based on long-short-term-memory networks. 2018 IEEE Texas Power and Energy Conference (TPEC), 1-6. https://doi.org/10.1109/TPEC.2018.8312088

Awal, M., \& Siddique, M. (2011). Rice production in Bangladesh employing by ARIMA model. Bangladesh Journal of Agricultural Research, 36(1), 51-62. https://doi.org/10.3329/bjar.v36i1.9229

BBC. (2021). Ever Given: Ship that blocked Suez Canal sets sail after deal signed. Retrieved on September 21, 2021, from https://www.bbc.com/news/world-middle-east$\underline{57746424}$

Burnham, K. P., \& Anderson, D.R. (Eds.), (2004). Model Selection and Multimodel Inference. Springer.

Chen, P., Niu, A., Liu, D., Jiang, W., \& Ma. B. (2018). Time series forecasting of temperatures using SARIMA: An example from Nanjing. IOP Conference Series: Materials Science and Engineering, 394(5), 052024. https://doi.org/10.1088/1757-899x/394/5/052024

Chou, M. -T. (2017). An improved fuzzy time series theory with applications in the Shanghai containerized freight index. Journal of Marine Science and Technology, 25(4), 393398. https://doi.org/10.6119/JMST-017-0313-1

Dasyam, R., Pal, S., Rao, V. S., \& Bhattacharyya, B. (2015). Time series modeling for trend analysis and forecasting wheat production of India. International Journal of Agriculture, Environment and Biotechnology, 8(2), 303308. https://doi.org/10.5958/2230-732X.2015.00037.6

Dickey, D. A., \& Fuller, W. A. (1979). Distribution of the estimators for autoregressive time series with a unit root. Journal of the American Statistical Association, 74(366a), 427-431. https://doi.org/10.1080/01621459.1979.10482531 
Dixon, M. (2010). Hedging your bets. Containerisation International Year Book., National Magazine Company.

Drewry. (2021). COVID-19 to stifle container port investment. Retrieved on September 21, 2021, from https://www.drewry.co.uk/news/covid-19-to-stiflecontainer-port-investment

Dunya. (2021). Retrieved on September 21, 2021, from https://www.dunya.com/sektorler/lojistik/noelsparisleri-one-cekildi-navlunda-yeni-zam-kapidahaberi-629042

Farhan, J., \& Ong, G. P. (2018). Forecasting seasonal container throughput at international ports using SARIMA models. Maritime Economics \& Logistics, 20, 131-148. https://doi.org/10.1057/mel.2016.13

Goulielmos, A. M., \& Psifia, M.-E. (2009). Forecasting weekly freight rates for one-year time charter $65000 \mathrm{dwt}$ bulk carrier, 1989-2008, using nonlinear methods. Maritime Policy \& Management, 36(5), 411-436. https://doi.org/10.1080/03088830903187150

Khogali, K. A., Odhiambo, J. W., \& Owino. J. O. (2002). On smoothing time series data using a classical moving average formula. Interstat: Statistics on the Internet, Retrieved on September 21, 2021, from https://www.researchgate.net/profile/John-Odhiambo3/publication/241913389 ON SMOOTHING TIME SERIE S DATA USING A CLASSICAL MOVING AVERAGE F ORMULA/links/58f78156aca2726498870d23/ONSMOOTHING-TIME-SERIES-DATA-USING-ACLASSICAL-MOVING-AVERAGE-FORMULA.pdf

Klein, A., \& Verbeke. A. (1987). The design of an optimal short term forecasting system for seaport management: an application to the port of Antwerp. International Journal of Transport Economics/Rivista internazionale di economia dei trasporti, 14(1), 57-70.
Lucas, J. M., \& Saccucci, M. S. (1990). Exponentially weighted moving average control schemes: Properties and enhancements. Technometrics, 32(1), 1-12. https://doi.org/10.1080/00401706.1990.10484583

Munim, Z. H., \& Schramm, H. -J. (2017). Forecasting container shipping freight rates for the Far East-Northern Europe trade lane. Maritime Economics \& Logistics, 19, 106-125. https://doi.org/10.1057/s41278-016-0051-7

Pang, G., \& Gebka, B. (2017). Forecasting container throughput using aggregate or terminal-specific data? The case of Tanjung Priok Port, Indonesia. International Journal of Production Research, 55(9), 2454-2469. https://doi.org/10.1080/00207543.2016.1227102

Shanghai Shipping Exchange. (2020). Shanghai Export Containerized Freight Index (SCFI). Retrieved on September 21, 2021, from http://en.sse.net.cn/

Ship Technology. (2021). Global shipping container shortage: the story so far. Retrieved on September 21, 2021, from https://www.ship-technology.com/features/globalshipping-container-shortage-the-story-so-far/

Shu, M. H., Nguyen, T. L., Hsu, B., Lu, C., \& Huang, J. -C. (2014). Forecasting cargo throughput with modified seasonal ARIMA models. WSEAS Transactions on Mathematics, 13, 171-181.

Stopford, M. (2009). Maritime Economics (3rd ed.). Routledge. Yang, Y., Zheng, H., \& Zhang, R. (2017). Prediction and analysis of aircraft failure rate based on SARIMA model. 2nd IEEE International Conference on Computational Intelligence and Applications (ICCIA), 2017, 567-571, https://doi.org/10.1109/CIAPP.2017.8167281 